\title{
Protection of Stone Monuments Using a Brushing Treatment with Ammonium Oxalate
}

\author{
Domagoj Mudronja $^{1, * \mathbb{D}}$, Frederik Vanmeert ${ }^{2}$, Stjepko Fazinic ${ }^{3}$, Koen Janssens ${ }^{2} \mathbb{D}$, Darko Tibljas ${ }^{4} \mathbb{D}$ and \\ Vladan Desnica 5
}

check for updates

Citation: Mudronja, D.; Vanmeert, F.; Fazinic, S.; Janssens, K.; Tibljas, D.; Desnica, V. Protection of Stone Monuments Using a Brushing Treatment with Ammonium Oxalate. Coatings 2021, 11, 379.

https://doi.org/10.3390/ coatings11040379

Received: 15 February 2021

Accepted: 23 March 2021

Published: 25 March 2021

Publisher's Note: MDPI stays neutral with regard to jurisdictional claims in published maps and institutional affiliations.

Copyright: (c) 2021 by the authors. Licensee MDPI, Basel, Switzerland. This article is an open access article distributed under the terms and conditions of the Creative Commons Attribution (CC BY) license (https:// creativecommons.org/licenses/by/ $4.0 /)$.
1 Croatian Conservation Institute, Grskoviceva 23, 10000 Zagreb, Croatia

2 Department of Physics, University of Antwerp, Groenenborgerlaan 171, B-2020 Antwerp, Belgium; frederik.vanmeert@uantwerpen.be (F.V.); koen.janssens@uantwerpen.be (K.J.)

3 Rudjer Boskovic Institute, Bijenicka c. 54, 10000 Zagreb, Croatia; stjepko.fazinic@irb.hr

4 Department of Geology, Faculty of Science, University of Zagreb, Horvatovac 95, 10000 Zagreb, Croatia; dtibljas@geol.pmf.hr

5 Department of Conservation-Restoration, Academy of Fine Arts, University of Zagreb, Ilica 85, 10000 Zagreb, Croatia; vdesnica@irb.hr

* Correspondence: dmudronja@hrz.hr

\begin{abstract}
Stone monuments and buildings are susceptible to weathering. Carbonate-based stones are especially vulnerable in acidic environments, whereas magmatic acidic stones are more susceptible to chemical weathering in basic environments. To slow down surface corrosion of limestone and marble artworks/buildings, protective coatings which inhibit calcite dissolution have been proposed. In this work, samples from two stone types with different porosity were treated with ammonium oxalate $(\mathrm{AmOx})$ to create a protective layer of calcium oxalate $(\mathrm{CaOx})$ using the previously developed brushing method. Two different synchrotron microscopy experiments were performed to determine its protective capability. X-ray powder diffraction (SR- $\mu$-XRPD) in transmission geometry allowed visualization of the distributions of calcium carbonate and oxalates along the sample depths. In a second step, X-ray fluorescence (SR- $\mu$-XRF) was used to check the efficiency/integrity of the protective surface coating layer. This was done by measuring the sulfur distribution on the stone surface after exposing the protected stones to sulfuric acid. XRPD showed the formation of a protective oxalate layer with a thickness of 5-15 $\mu \mathrm{m}$ on the less porous stone, while a $20-30 \mu \mathrm{m}$ thick layer formed on the more porous stone. The XRF study showed that the optimal treatment time depends on the stone porosity. Increasing the treatment time from 1 to $3 \mathrm{~h}$ resulted in a decreased efficiency of the protective layer for the low porosity stone. We assume that this is due to the formation of vertical channels (cracks) in the protective layer.
\end{abstract}

Keywords: ammonium oxalate; calcium oxalate; stone monuments; synchrotron based $\mu \mathrm{XRD}$; synchrotron based $\mu \mathrm{XRF}$

\section{Introduction}

In all historical time periods up to the present day, limestone and marble have been commonly used building materials. However, due to their mineral composition and porosity they are susceptible to weathering, especially in acidic environments often caused by air pollution which leads to dissolution of calcite $\left(\mathrm{CaCO}_{3}\right)$. The dissolution rate of calcite is a function of $\mathrm{pH}$, amounting to $\sim 10^{-10} \mathrm{~mol} /\left(\mathrm{cm}^{2} \mathrm{~s}\right)$ at $\mathrm{pH} 5.6$ [1] and notably increases with lower $\mathrm{pH}$ [2]. To slow down or even prevent surface corrosion of limestone and marble artworks/buildings, protective coatings which inhibit calcite dissolution have been proposed. There have been two main routes pursued: (i) the development of organic protectives that modify the wettability of marble surfaces and (ii) the development of inorganic protectives that form a superficial layer with reduced (acid) solubility [3]. Although effective, organic protectives (such as acrylic resins and fluorinated polymers) exhibit several limitations 
in terms of their compatibility with the stone substrate as well as their durability $[3,4]$. Recently, novel organic coatings based on methacrylate co-polymers have been developed for cultural heritage $[5,6]$. In turn, inorganic protectives generally exhibit a limited effectiveness $[3,7]$. The most widely used inorganic treatment aims to form a passivating layer of calcium oxalate monohydrate (whewellite) that covers the marble surface. Calcium oxalate $(\mathrm{CaOx})$ is formed through the reaction of calcite $\left(\mathrm{CaCO}_{3}\right)$ with an aqueous solution of ammonium oxalate (AmOx) [3,8,9]. In the last few years, several alternatives to AmOx for the formation of a protective calcium oxalate layer have been investigated. The ammonium salts of oxamate (AmOxam) and monomethyloxalate (AmMeox), structurally related to AmOx, were synthesized and characterized as protecting agents/fillers for calcareous stone substrates. Both compounds feature an improved solubility in water and alcoholic-water mixtures with respect to AmOx [10]. Furthermore, a treatment with oxalic acid has been investigated for the formation of protective $\mathrm{CaOx}$ rims on marble surface [11]. The created $\mathrm{CaOx}$ rims on the surface of marble showed a higher acid resistance [11], but an acidic treatment of carbonate-based stones remains questionable from a conservator point of view. From 2011, an alternative approach to calcium oxalate has been explored in the form of hydroxyapatite (HAP) and calcium phosphates (CaP) [12]. Although in some ways superior to calcium oxalate protection, its application still shows some problems. For instance, even small amounts of magnesium significantly alter the formation of calcium phosphates [12].

In our previous research $[13,14]$, we developed a procedure for applying ammonium oxalate (AmOx) by a brushing method with the aim of protecting monumental limestone objects. The efficiency of the brushing procedure for creating the protective $\mathrm{CaOx}$ layer was compared with the typical poultice treatment and with an immersion method. Synchrotronbased X-ray powder diffraction (SR-XRPD) measurements carried out in reflection mode revealed that whewellite $\left(\mathrm{CaC}_{2} \mathrm{O}_{4} \cdot \mathrm{H}_{2} \mathrm{O}\right)$ and weddellite $\left(\mathrm{CaC}_{2} \mathrm{O}_{4} \cdot 2 \mathrm{H}_{2} \mathrm{O}\right)$ readily formed on the samples treated by AmOx brushing [13]; while for the other methods (poultice and immersion), only whewellite was formed. The thickness of the whewellite layer did not exceed $40 \mu \mathrm{m}$ and no clear relation between the thickness of the formed oxalate layer and the treatment time could be observed. SR- $\mu$-FTIR measurements showed that the surface of the treated stone was not evenly covered with calcium oxalate at the microscopic level [13]. This was consistent with SEM observations of the treated surfaces that showed that $\mathrm{CaOx}$ was growing in clusters, resulting in an uneven surface coverage. Longer treatment times gave rise to larger oxalate crystals.

The aim of the present work has been to obtain a more detailed insight into the formation of the protective calcium oxalate layer on stone monument surfaces and to further optimize the ammonium oxalate treatment following the brushing method. In the first part of this research, selected limestone (Veselje) and marble (Carrara) model samples with different porosity were treated using the previously developed brushing method [13] to increase the acid resistance of the stone. Using SR- $\mu$-XRPD mapping experiments in transmission mode on sheet-shaped subsamples of the treated stones, the depth distribution of the created protective layers could be analyzed. For the second part of this research, the treated stones were exposed to $2 \%$ sulfuric acid for a period of $1 \mathrm{~min}$. While SR-FTIR micro-scanning was used in our previous study to map the oxalate distribution on the surface of the treated stones [14], the quality of the obtained spectral datasets was limited because of large Reststrahlen bands which resulted in a high background noise. Therefore, in the present study, the formation of gypsum, which is the result of the reaction between calcite and the acid, is monitored using scanning SR- $\mu$-XRF, exploiting the fact that sulfur is only present in trace quantities in marble and limestone building materials.

\section{Materials and Methods}

\subsection{Materials}

For this research two types of stones were selected: Cretaceous limestone, commercially called Veselje, and Carrara marble. Veselje is a light-grey limestone mainly composed 
of rudist shell clasts and has a porosity of $6.2 \%$. Petrologically it is determined as bioclastic packestone/wackestone to bioclastic floatstone. Carrara marble is a white marble characterized by a granoblastic polygonal structure with subrectilinear contacts among the calcite crystals with porosity of $2 \%$.

AmOx solutions (5\%) were prepared from ammonium oxalate monohydrate $99.5 \%$ $\left(\mathrm{C}_{2} \mathrm{H}_{8} \mathrm{~N}_{2} \mathrm{O}_{4} \cdot \mathrm{H}_{2} \mathrm{O}\right.$ ), CAS No. 6009-70-7 (Acros Organics, part of Thermo Fisher Scientific, Geel, Belgium). A mixture of 2/3 arbocel 1000 and 1/3 arbocel 200 was used as poultice.

A solution of sulfuric acid (2\%, pH 3) was made using sulfuric acid (95-97\%) from Merck KGaA, Darmstadt, Germany, buffered to $\mathrm{pH} 3$ with $\mathrm{NH}_{4} \mathrm{OH}$ (25\%) from Alkaloid AD Skopje, Republic of North Macedonia.

For the preparation of the thin sections for the SR- $\mu$-XRPD investigations, polycarbonate sheets with dimensions of $50 \times 20 \times 1 \mathrm{~mm}^{3}$ were used. Samples were glued to the polycarbonate sheets with Canada balsam, CAS No. 8007-47-4 (Kremer Pigmente GmbH \& Co.KG, Aichstetten, Germany).

\subsection{Sample Preparation}

Both stone types were first cut to $5 \times 2.5 \times 3 \mathrm{~cm}^{3}$ parallelepipeds. After that, they were treated with 5\% AmOx solution following 1 and $3 \mathrm{~h}$ brushing treatments [13]. Approximately $2 \mathrm{~mL}$ of $5 \%$ AmOx solution was used to cover $1 \mathrm{~cm}^{2}$ of stone surface during $1 \mathrm{~h}$ brushing treatment (ten $1 \mathrm{~min}$ brushing cycles every 6 min during $1 \mathrm{~h}$ ) [13]. To facilitate the SR- $\mu$-XRPD investigations, $2 \mathrm{~mm}$ thick sections were made. For this reason, after $24 \mathrm{~h}$ of drying, the samples were glued with Canada balsam to polycarbonate sheets. After the glue dried, $2 \mathrm{~mm}$ thick thin sections were made by cutting the part from the parallelepiped that was not glued to the polycarbonate sheets. The polycarbonate sheets provided a good support for the stone samples during the cutting process and prevented the thin sections from crumbling. No visible cracks or damage induced by the mechanical cutting was noted on the $2 \mathrm{~mm}$ thin sections.

A second set of samples was prepared from Veselje limestone and Carrara marble treated with 5\% AmOx solution, again using 1 and $3 \mathrm{~h}$ brushing treatments [13]. After thorough drying for one week, the samples were exposed to $2 \%$ sulfuric acid ( $\mathrm{pH} 3$ ) for one minute using a poultice. After acid exposure, the samples were washed by immersion in deionized water for 1-2 s to wash out any unreacted acid. After drying, small cubes of $5 \times 5 \times 5 \mathrm{~mm}^{3}$ were cut out from the larger stone blocks for SR- $\mu$-XRF analysis.

\subsection{Analytical Techniques}

Before and after the AmOx treatment, colorimetric measurements were carried out to observe possible color changes of the stone surface induced by the treatment. Colorimetric measurements were carried out using a fiber optics reflectance spectrometer under a $45^{\circ} / 45^{\circ}$ geometry, employing an Ocean Optics USB4000 spectrometer (Ocean Insight, Ostfildern, Germany) coupled with an HL-2000 halogen lamp, standard illuminant D65 and observer $2^{\circ}$. The colorimetric properties and reflectance spectra were recorded on untreated and treated samples on the exact same position and under the same orientation. To evaluate changes in sample color a CIE $1976 \mathrm{~L}^{*} \mathrm{a}^{*} \mathrm{~b}^{*}$ color system was used, where a color difference between two measurements is simply calculated as the Euclidean distance in CIELab color space and denoted as $\Delta E^{*}$. A value for $\Delta E^{*}$ under 2.3 is regarded as a value below which not even a trained observer's eye can notice the difference [15], for $\Delta E^{*}<3$ the effect is hardly perceptible, for $3<\Delta E^{*}<6$ is perceptible but acceptable, and for $6<\Delta E^{*}$ two colors are regarded as being different [16].

In order to visualize the depth profiles and surface distributions of the created protective oxalate layers, SR- $\mu$-XRPD (Synchrotron SOLEIL, L'Orme des Merisiers Saint-Aubin, France) was performed on the $2 \mathrm{~mm}$ thin samples.

SR- $\mu$-XRPD measurements were performed at the DiffAbs beamline of SOLEIL (SaintAubin, France). Thin sections of the samples were measured in transmission geometry using a focused X-ray beam $\left(10.5 \times 6.5 \mu \mathrm{m}^{2}\right.$ (hor. $\times$ vert.) $)$ with a primary energy of about 
$18.5 \mathrm{keV}$. XRD patterns were collected using a Rayonix SX165 area detector (Rayonix, L.L.C. Evanston, IL, USA) positioned about $55 \mathrm{~cm}$ behind the sample. On each sample, a mapping experiment was performed with a step size of $10 \times 5 \mu \mathrm{m}^{2}$ (hor. $\times$ vert.) and an acquisition time of $10 \mathrm{~s}$ per pixel. Each map consisted of 21 vertical lines covering a horizontal area of $200 \mu \mathrm{m}$. The diffraction patterns (Figure 1) were analyzed by the XRDUA software package [17].

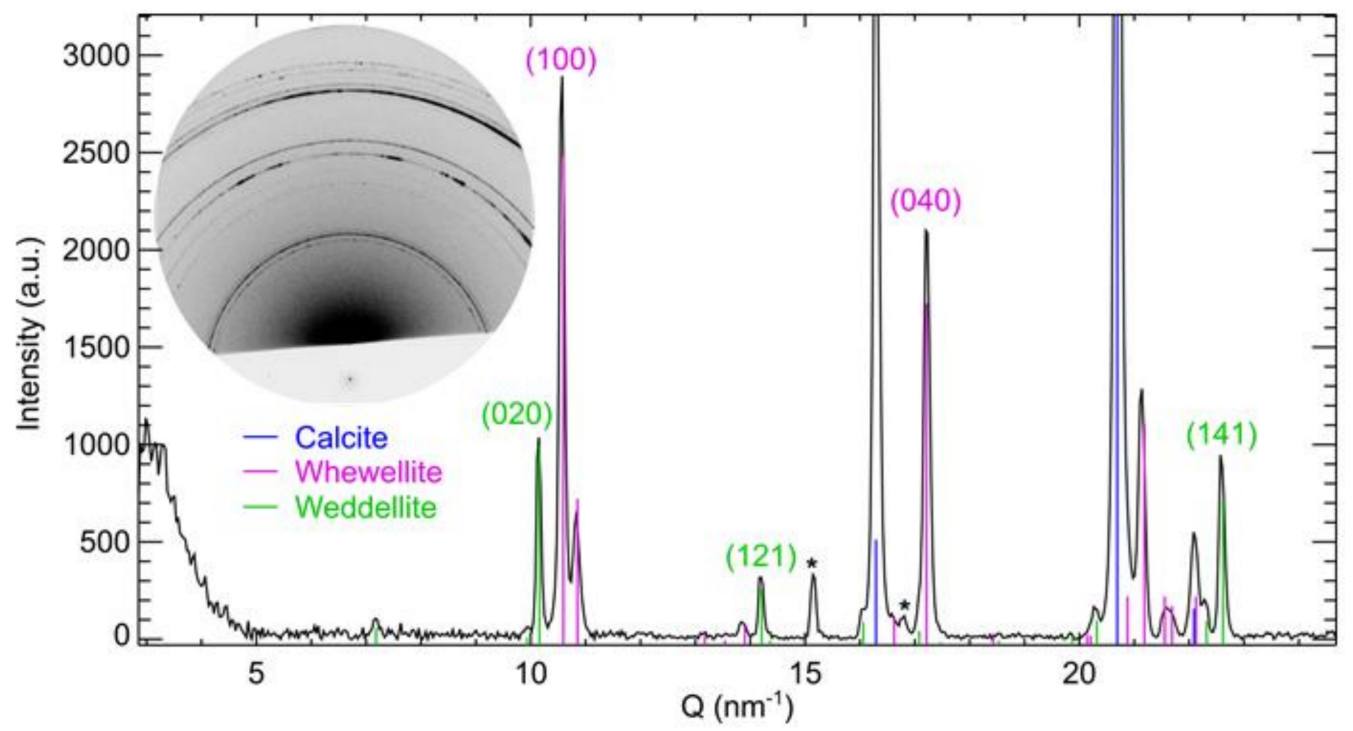

Figure 1. Diffractogram obtained on sample VES_A5_3 after an exposure of $10 \mathrm{~s}$ showing the presence of calcite (blue), weddellite (green), and whewellite (pink). The Miller indices for the reflections of weddellite and whewellite that are used for the calculation of the layer thickness and penetration depth are given. The ${ }^{* \prime}$ symbols indicate diffraction signals originating from the dried glue. The inset shows the corresponding 2D diffraction image. The lower intensity in the bottom part of the diffraction image is due to a lead foil that was added to protect the detector from the primary.

In order to test the integrity and efficiency of the created protective layers, samples from the second set were measured using $\mu$-XRF at the XRF end-station, Elettra synchrotron facility in Trieste. The surfaces of the treated model samples that were exposed to sulfuric acid were scanned using a primary X-ray beam of $3850 \mathrm{eV}$ and a beam size of $50 \times 250 \mu \mathrm{m}^{2}$. Surface areas of about $5 \times 5 \mathrm{~mm}^{2}$ or $8 \times 8 \mathrm{~mm}^{2}$ were analyzed with steps of $0.3 \times 0.15 \mathrm{~mm}^{2}$ and $5 \mathrm{~s}$ dwell time in order to map sulfur $\mathrm{K} X$-ray intensities. The primary beam energy was set to $3850 \mathrm{eV}$ to avoid large Ca-K XRF signals from the samples. This was necessary since Ca-K escape peaks coincide with the S-K $\alpha$ signal, as demonstrated in Figure 2. Twodimensional surface distribution maps of sulfur were measured as well as cumulative sulfur intensities over the measured areas spanning 25 and $64 \mathrm{~mm}^{2}$. The XRF data was analyzed using Origin statistical software for the creation of the surface distribution maps. 


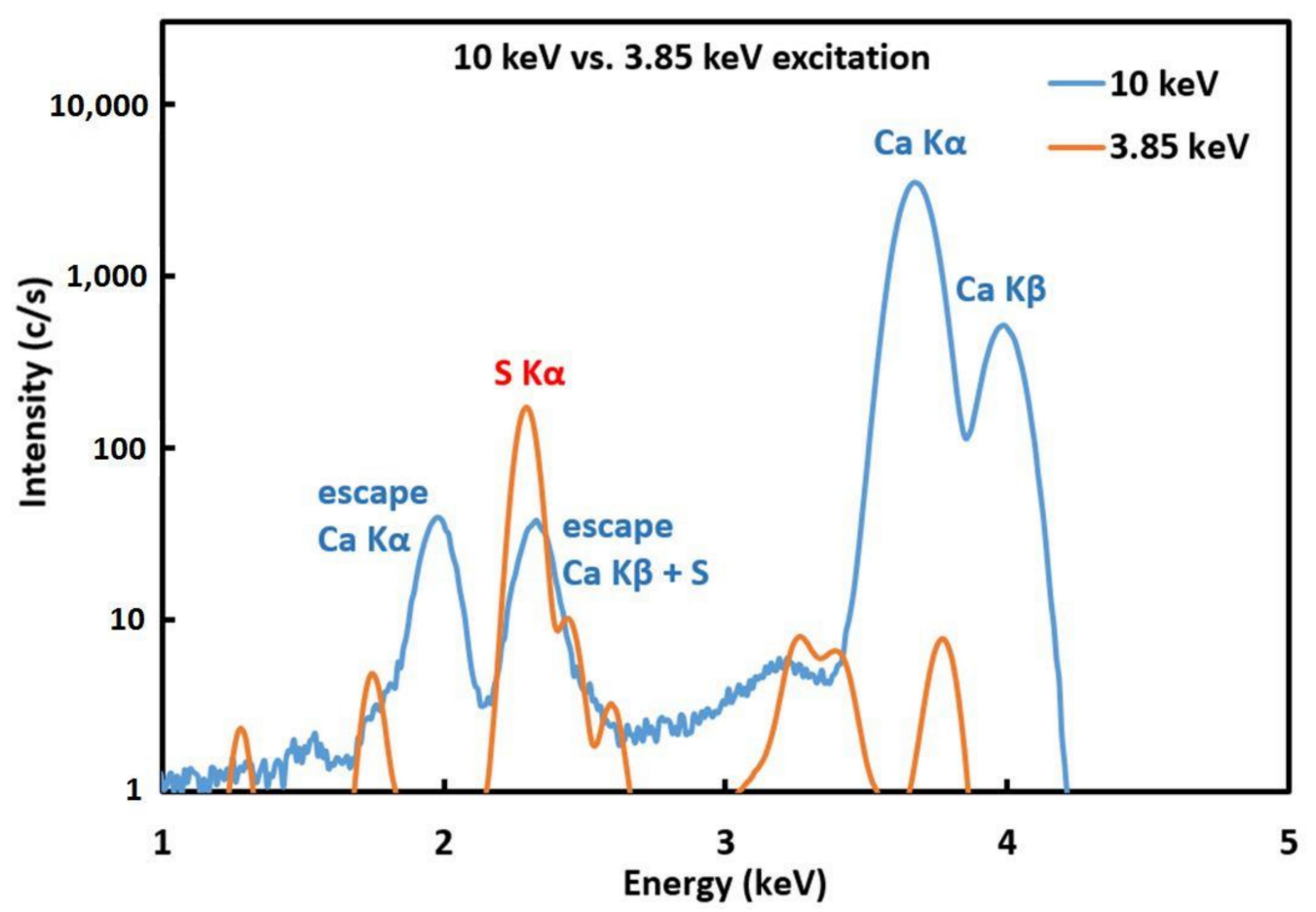

Figure 2. Comparison of XRF spectra on Carrara marble samples obtained with $3.85 \mathrm{keV}$ and $10 \mathrm{keV}$ excitation energies.

\section{Results and Discussion}

\subsection{Colorimetric Analysis of Stone Surface}

Colorimetric analysis carried out on the samples before and after the treatment showed only slight changes in color. The $\Delta E^{*}$ values for Carrara marble after 1 and $3 \mathrm{~h}$ and Veselje limestone after 1 and $3 \mathrm{~h}$ compared to the untreated surfaces were $\Delta E^{*} C A R A 5 \_1=2.07$, $\Delta E^{*}$ CAR A5_3 $=4.98, \Delta E^{*}$ VES A5_1 $=2.77$, and $\Delta E^{*} V E S$ A5_3 $=0.35$, respectively. Therefore, it can be concluded that the proposed treatment does not significantly modify the color of the stone surfaces.

\subsection{Thickness of Oxalate Protective Layers}

Depth profiles were defined using the approach that was followed in our previous research [13]. A total of two criteria for the calcium oxalate layer thickness were defined: the depth after which the amount of whewellite dropped below $50 \%$ of the amount measured on the surface (thickness of the protective layer) and the depth after which no more oxalate was observed (penetration depth). These values were determined by using a Gaussian profile function for single-peak fitting of several intense diffraction peaks of the phases under investigation, i.e., reflection (020), (121) and (141) for weddellite, and (100) and (040) for whewellite, see Table 1. For the limit of detection, it was taken that the peak height of the respective weddellite or whewellite diffraction line needed to be larger than 10 times the standard deviation of the background signal.

Comparison of the two brushing treatments ( 1 and $3 \mathrm{~h}$ treatment) on two different stones showed that on the less porous Carrara marble the thickness of the oxalate layer increased with longer treatments, from $6 \mu \mathrm{m}$ to $11 \mu \mathrm{m}$ and $9 \mu \mathrm{m}$ to $17 \mu \mathrm{m}$, respectively for weddellite (WD) and whewellite (WH) (see Table 1). Furthermore, the penetration depth of both weddellite and whewellite significantly increases with longer treatment times, from $10 \mu \mathrm{m}$ to $25 \mu \mathrm{m}$ for WD and from $20 \mu \mathrm{m}$ to $30 \mu \mathrm{m}$ for WH (Table 1). An increase in the measured diffraction intensity of both calcium oxalates is visible for the $3 \mathrm{~h}$ treatment (Figure 3 ). 
Table 1. Oxalate layer thickness and penetration depth for the Carrara marble (CAR) and Veselje limestone (VES) for $1 \mathrm{~h}$ (A5_1) and $3 \mathrm{~h}$ (A5_3). Values shown are averaged over the entire map (21 lines) with standard deviations (1 s) in parentheses. $\mathrm{WD}=$ weddellite; $\mathrm{WH}=$ whewellite.

\begin{tabular}{|c|c|c|c|c|c|}
\hline \multicolumn{6}{|c|}{ Oxalate Layer Thickness $(\mu \mathrm{m})$} \\
\hline & WD (020) & WD (121) & WD (141) & WH (100) & WH (040) \\
\hline CAR_A5_1 & $6(2)$ & $6(2)$ & $6(2)$ & $10(7)$ & $8(3)$ \\
\hline CAR_A5_3 & $11(9)$ & $11(8)$ & $13(9)$ & $18(9)$ & $17(8)$ \\
\hline VES_A5_1 & $11(9)$ & $12(9)$ & $13(9)$ & $17(8)$ & $15(7)$ \\
\hline VES_A5_3 & $9(3)$ & $10(3)$ & $11(3)$ & $12(3)$ & $11(2)$ \\
\hline \multicolumn{6}{|c|}{ Oxalate Penetration Depth $(\mu \mathrm{m})$} \\
\hline & WD (020) & WD (121) & WD (141) & WH (100) & WH (040) \\
\hline CAR_A5_1 & $12(2)$ & $11(3)$ & $12(3)$ & $21(6)$ & $21(8)$ \\
\hline CAR_A5_3 & $25(10)$ & $24(7)$ & $28(7)$ & $32(5)$ & $29(5)$ \\
\hline VES_A5_1 & $21(10)$ & $17(9)$ & $29(6)$ & $80(27)$ & $85(22)$ \\
\hline VES_A5_3 & $19(7)$ & $20(5)$ & $22(5)$ & 212 (93) & $188(78)$ \\
\hline
\end{tabular}
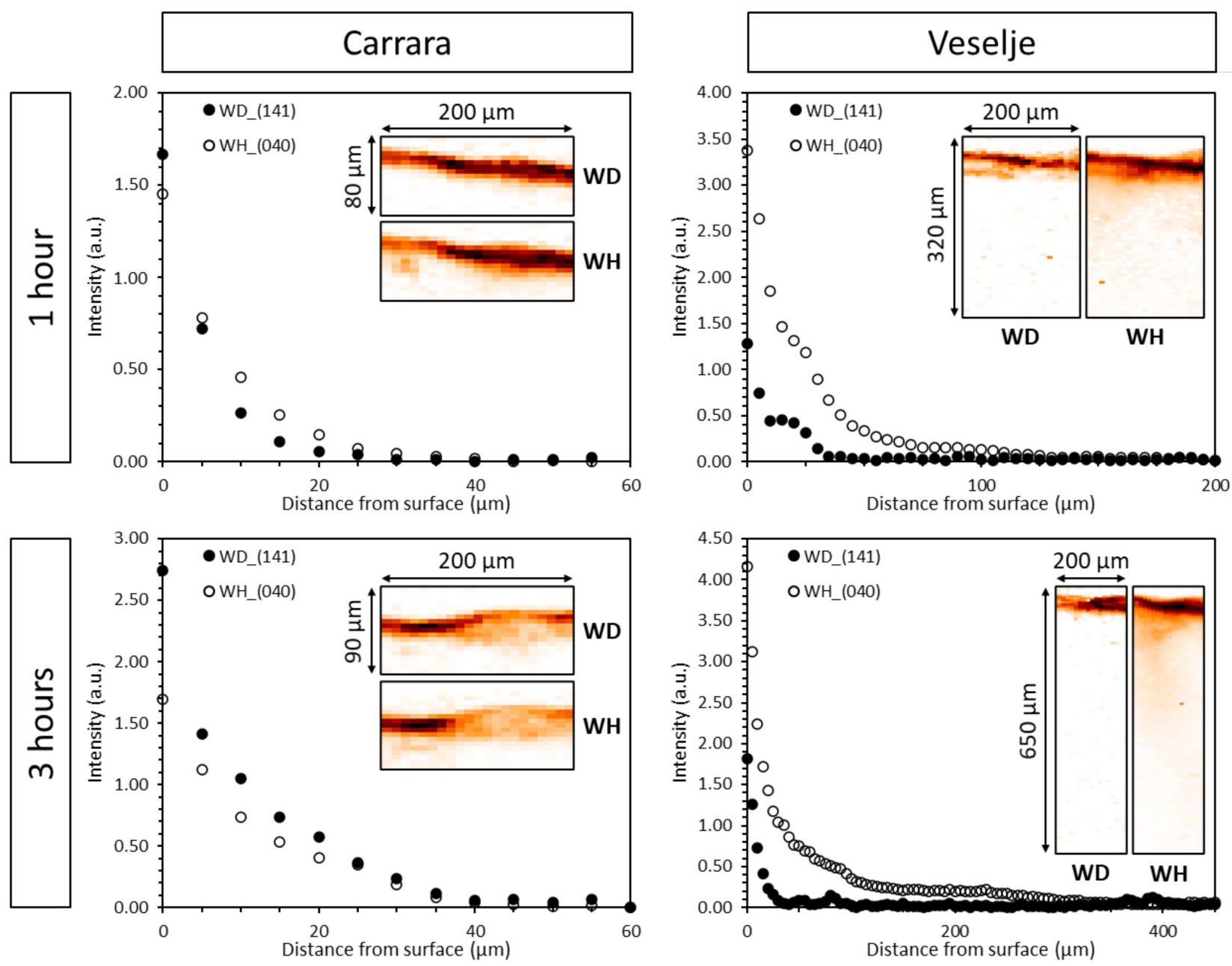

Figure 3. Depth profiles of weddellite (141) and whewellite (040) reflections for Carrara marble (left) and Veselje limestone (right) for the brushing treatment of $1 \mathrm{~h}$ (top) and $3 \mathrm{~h}$ (bottom). These profiles are the averaged results over the entire map (21 lines). The corresponding distribution maps of weddellite and whewellite are shown as insets in each graph. The darker color indicates a higher oxalate intensity at the top of the sample. 
On the more porous Veselje stone, the thickness of the protective layer (Table 1 and Figure 3) remained unchanged for both treatment times $(<15 \mu \mathrm{m})$. The penetration depth of weddellite (Table 1) also showed approximately the same for both treatment times (roughly $20 \mu \mathrm{m}$ ), while the penetration depth of whewellite showed a strong increase, around $200 \mu \mathrm{m}$ with the $3 \mathrm{~h}$ treatment compared to $80 \mu \mathrm{m}$ for the $1 \mathrm{~h}$ treatment. The diffraction intensity of whewellite for the $3 \mathrm{~h}$ treatment dropped rapidly over a depth of $50 \mu \mathrm{m}$. Again, the measured diffraction intensity of both calcium oxalates in the protective layer was higher for the longer treatment time, showing the increased formation of both oxalates close to/at the surface of the stones (Figure 3). Because of the higher porosity of Veselje limestone, the AmOx solution can more easily penetrate deeper within the calcite matrix, giving rise to a thicker protective oxalate layer.

\subsection{Efficiency of Oxalate Protective Layers}

Figure 4 shows two-dimensional S-K XRF maps obtained at the Elettra XRF beam line for the Veselje limestone treated with brushing $1 \mathrm{~h}$ (up) and $3 \mathrm{~h}$ (down) treatments after exposure to sulfuric acid together with the photomicrograph of the related stones.
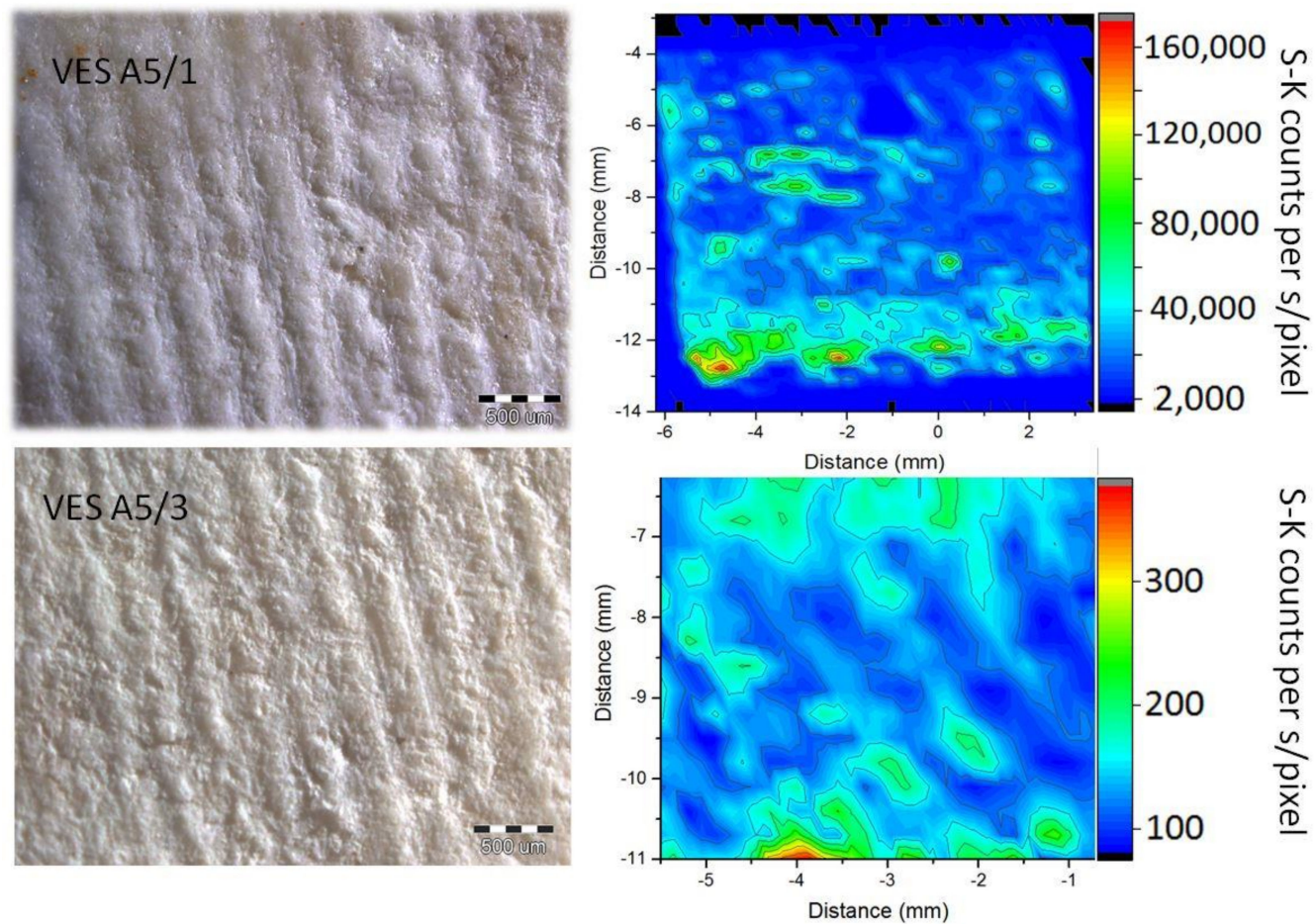

Figure 4. Right: 2D S-K XRF map from the surface of the Veselje limestone treated with AmOx brushing for $1 \mathrm{~h}(\mathbf{u p})$ and $3 \mathrm{~h}$ (down) after exposure to sulfuric acid. Left: photomicrograph of related stones.

The $2 \mathrm{D}$ map related to the $1 \mathrm{~h}$ treatment was obtained with an exposure time of $0.5 \mathrm{~s} /$ pixel, while for the $3 \mathrm{~h}$ treatment an exposure time of $10 \mathrm{~s} /$ pixel was used. For the sake of clarity, the corresponding intensity scales presented at the right side of the maps are adjusted to sulfur K X-ray counts per second/pixel for both maps. It is clear that the amount of sulfur shown in the maps is much lower for the treatment of $3 \mathrm{~h}$ when compared to the map related to the $1 \mathrm{~h}$ treatment. Since the presence of sulfur can be linked to the formation of gypsum, this clearly indicates that the $3 \mathrm{~h}$ treatment is much more efficient at protecting the surface of the stones from acids than the $1 \mathrm{~h}$ treatment. Indeed, in the areas that are not efficiently covered by the protective oxalate layer, gypsum will be created $\left(2 \mathrm{CaCO}_{3}+2 \mathrm{H}_{2} \mathrm{SO}_{4} \rightarrow 2 \mathrm{CaSO}_{4} \cdot 2 \mathrm{H}_{2} \mathrm{O}+2 \mathrm{CO}_{2} \uparrow\right)$, yielding a high S-K XRF intensity. On the other hand, in areas that are efficiently covered with the oxalate protective layer, gypsum will not form. 
We can also compare cumulative S K X-ray intensity rates for both maps by summing the contributions from all the pixels and normalizing them to the total collection time.

Figure 5 shows such normalized cumulative XRF spectra obtained for the brushing treatments of both Veselje limestone and Carrara marble for one and three hours. In the case of Veselje limestone, the $3 \mathrm{~h}$ brushing treatment showed a much lower cumulative sulfur signal rate compared to the $1 \mathrm{~h}$ treatment. This is in line with the above conclusion from the comparison of the 2D maps, and confirms that on average the protective layer after $3 \mathrm{~h}$ treatment functions more efficiently compared to the $1 \mathrm{~h}$ treatment. However, in the case of Carrara marble, an unexpected result was obtained. For Carrara marble, the $1 \mathrm{~h}$ brushing treatment showed a lower sulfur cumulative signal rate compared to the $3 \mathrm{~h}$ treatment, indicating that less $\mathrm{CaSO}_{4} \cdot 2 \mathrm{H}_{2} \mathrm{O}$ is formed after the shorter treatment time. This suggests that the $3 \mathrm{~h}$ treatment yields a poorer protective layer for Carrara marble. For marble that was not exposed to sulfuric acid the detected presence of sulfur is negligible (as it should be the case for both marble and Veselje limestone), confirming that creation of gypsum on the stone surface is the only source of sulfur.
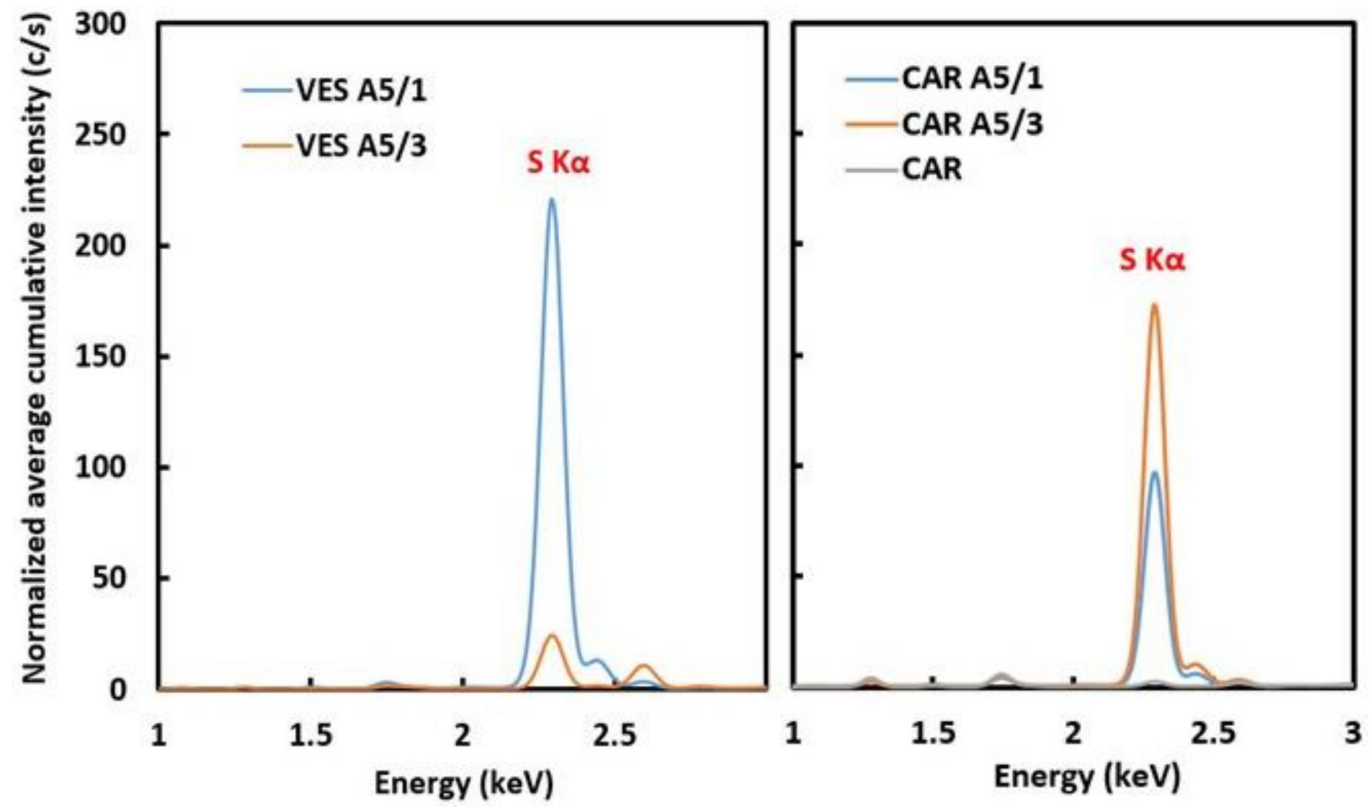

Figure 5. Cumulative XRF spectra showing count rates (c/s) for S-K X-rays for the 1 (A5/1) and 3 h (A5/3) brushing treatment of Veselje limestone (left) and Carrara marble (right) A negligible amount of sulfur present in untreated marble is also shown (CAR).

This unexpected result seems to be in line with the recent findings published in 2018 [18]. A possible explanation for these results could be found in the formation of vertical channels that penetrate the $\mathrm{CaOx}$ protective layer. These channels are necessary for the AmOx solution to reach the underlying calcium carbonate, which corresponds with the findings from Sassoni et al. [12]. The channels are formed after the original calcium carbonate surface is covered with the $\mathrm{CaOx}$ protective layer, and $\mathrm{AmOx}$ is still present on the surface. In this case, such vertical channels would allow AmOx to reach the underlying calcium carbonate. Consequently, sulfuric acid can also use these channels to reach the calcite substrate, giving rise to an increased formation of gypsum, hence increasing the measured S-K XRF intensity for the longer treatment time on the less porous Carrara Marble.

\section{Conclusions}

SR- $\mu$-XRPD imaging in transmission mode of the protective CaOx layer on less porous Carrara marble showed that the thickness of the protective layer is between 5 and $15 \mu \mathrm{m}$ depending on the treatment time. Both whewellite and weddellite were found until depths 
of $30 \mu \mathrm{m}$ below the stone surface. On the more porous limestone (Veselje), the thickness of the protective layer is between 10 and $15 \mu \mathrm{m}$ irrespective of the treatment time. The formation of whewellite reaches depths up to $200 \mu \mathrm{m}$, whereas weddellite forms only at depths up to $30 \mu \mathrm{m}$. A longer treatment time creates a slightly thicker protective layer for the less porous stone (approximately $5 \mu \mathrm{m}$ thicker), whereas on the more porous stone the effect of treatment time on the thickness of the protective layer seems negligible. On Veselje limestone, thicker protective layers are formed than on the Carrara marble because of the difference in porosity. Indeed, a higher porosity allows the AmOx solution to react more easily with calcite that lies deeper underneath the surface.

The evaluation of the integrity and effectiveness of the $\mathrm{CaOx}$ protective layer following the exposure to sulfuric acid showed somewhat unexpected results. On Veselje limestone, the brushing treatment of $3 \mathrm{~h}$ clearly showed a decrease in the formation of gypsum, indicating a better surface protection by the oxalate layer when compared to the $1 \mathrm{~h}$ treatment. However, on the less porous marble an opposite result was obtained. Carrara marble stones treated with the brushing method for $3 \mathrm{~h}$ showed a much higher S-K XRF intensity compared to the $1 \mathrm{~h}$ treatment. This indicates that the integrity of the protective layer decreases from a one-hour to a three-hour treatment, possibly due to the creation of vertical channels in the protective layer.

For real monuments, the creation of these vertical channels will lead to an increased penetration of water or acidic rain leading to the breakup of the protective layer. The difference in time frame for the development of these vertical channels, and hence the destruction of the protective layer between marble and limestone, can be connected to the difference in the porosity between the different stone types. To overcome this problem, it should be necessary to finalize the AmOx treatment of stone monuments once the protective $\mathrm{CaOx}$ layer is formed on the surface. Therefore, we can conclude that for the brushing treatment with $\mathrm{AmOx}$ of marble with $2 \%$ porosity, the treatment should not proceed for longer than $1 \mathrm{~h}$. In case of the limestone with $7 \%$ porosity, brushing treatment can continue to at least $3 \mathrm{~h}$.

Further tests on stones with a different porosity are needed to better estimate the required treatment brushing treatment time. Furthermore, the effect of the treatment time of the alternative poultice treatment on the integrity of the protective layers also needs to be tested.

Author Contributions: Conceptualization, D.M. and D.T.; methodology, D.M., F.V., and D.T.; software, F.V.; validation, F.V.; formal analysis, D.M., F.V., S.F. and V.D.; investigation, D.M., F.V., and S.F.; resources, D.M. and F.V.; data curation, F.V. and S.F.; writing-original draft preparation, D.M. and S.F.; writing-review and editing, F.V., D.T., K.J., and V.D.; supervision, S.F. and K.J.; project administration, S.F. and K.J.; funding acquisition, S.F. and K.J. All authors have read and agreed to the published version of the manuscript.

Funding: Part of this research was supported through the FWO IRI Grant "Dubble/ESRF" I001919N. Another part of this research was funded within the framework of the IAEA CRP1917 RC No. 18227. Furthermore, the research had financial support from the European Regional Development Fund for the 'Center of Excellence for Advanced Materials and Sensing Devices' (Grant No. KK.01.1.1.01.0001).

Institutional Review Board Statement: Not applicable.

Informed Consent Statement: Not applicable.

Data Availability Statement: Deposited dataset: https:/ /data.mendeley.com/datasets/dvck37fxf5 $/ 1$ (accessed on 11 May 2020).

Acknowledgments: We acknowledge SOLEIL for beam time granted (proposal 20131138) and provision of synchrotron radiation facilities and we thank Cristian Mocuta for assistance in using the DiffAbs beamline. We also thank Juan José Leani and Andreas Karydas for assistance in using the XRF end-station (Elettra).

Conflicts of Interest: The authors declare no conflict of interest. 


\section{References}

1. Brady, P.V. Physics and Chemistry of Mineral Surfaces; CRC Press: New York, NY, USA, 1996.

2. Naidu, S.; Blair, J.; Scherer, G.W. Acid-Resistant Coatings on Marble. J. Am. Ceram. Soc. 2016, 99, 3421-3428. [CrossRef]

3. Sassoni, E.; Graziani, G.; Franzoni, E.; Scherer, G.W. Calcium phosphate coatings for marble conservation: Influence of eth-anol and isopropanol addition to the precipitation medium on the coating microstructure and performance. Corros. Sci. 2018, 136, 255-267. [CrossRef]

4. Carretti, E.; Dei, L. Physicochemical characterization of acrylic polymeric resins coating porous materials of artistic interest. Prog. Org. Coat. 2004, 49, 282-289. [CrossRef]

5. Sabatini, V.; Pargoletti, E.; Comite, V.; Ortenzi, M.A.; Fermo, P.; Gulotta, D.; Cappelletti, G. Towards Novel Fluorinated Methacrylic Coatings for Cultural Heritage: A Combined Polymers and Surfaces Chemistry Study. Polymers 2019, 11, 1190. [CrossRef] [PubMed]

6. Sabatini, V.; Pargoletti, E.; Longoni, M.; Farina, H.; Ortenzi, M.A.; Cappelletti, G. Stearyl methacrylate co-polymers: Towards new polymer coatings for mortars protection. Appl. Surf. Sci. 2019, 488, 213-220. [CrossRef]

7. Hansen, E.F.; Doehne, E.; Fidler, J.M.; Larson, J.D.; Martin, B.R.; Matteini, M.; Rodriguez-Navarro, C.; Pardo, E.S.; Price, C.; De Tagle, A.; et al. A review of selected inorganic consolidants and protective treatments for porous calcareous materials. Stud. Conserv. 2003, 48, 13-25. [CrossRef]

8. Matteini, M. Inorganic treatments for the consolidation and protection of stone artefacts. Conserv. Sci. Cult. Herit. 2008, 8, 13-27.

9. Dreyfuss, T. Interactions on site between powdering porous limestone, natural salt mixtures and applied ammonium oxalate. Herit. Sci. 2019, 7, 5. [CrossRef]

10. Maiore, L.; Aragoni, M.C.; Carcangiu, G.; Cocco, O.; Isaia, F.; Lippolis, V.; Meloni, P.; Murru, A.; Tuveri, E.; Arca, M. Synthesis, characterization and DFT-modeling of novel agents for the protection and restoration of historical calcareous stone substrates. $J$. Colloid Interface Sci. 2015, 448, 320-330. [CrossRef] [PubMed]

11. Burgos-Cara, A.; Ruiz-Agudo, E.; Rodriguez-Navarro, C. Effectiveness of oxalic acid treatments for the protection of marble surfaces. Mater. Des. 2017, 115, 82-92. [CrossRef]

12. Sassoni, E. Hydroxyapatite and Other Calcium Phosphates for the Conservation of Cultural Heritage: A Review. Materials 2018, 11, 557. [CrossRef] [PubMed]

13. Mudronja, D.; Vanmeert, F.; Hellemans, K.; Fazinic, S.; Janssens, K.; Tibljas, D.; Rogosic, M.; Jakovljevic, S. Efficiency of applying ammonium oxalate for protection of monumental limestone by poultice, immersion and brushing methods. Appl. Phys. A 2012, 111, 109-119. [CrossRef]

14. Vanmeert, F.; Mudronja, D.; Fazinić, S.; Janssens, K.; Tibljas, D. Semi-quantitative analysis of the formation of a calcium oxalate protective layer for monumental limestone using combined micro-XRF and micro-XRPD. X-ray Spectrom. 2013, 42, $256-261$. [CrossRef]

15. Mahy, M.; Van Eycken, L.; Oosterlinck, A. Evaluation of uniform color spaces developed after the adoption of CIELAB and CIELUV. Color Res. Appl. 1994, 19, 105-121. [CrossRef]

16. Hardeberg, J.Y. Acquisition and Reproduction of Color Images: Colorimetric and Multispectral Approaches; Universal-Publishers: Irvine, CA, USA, 2001; ISBN 1-58112-135-0.

17. De Nolf, W.; Vanmeert, F.; Janssens, K. XRDUA: Crystalline phase distribution maps by two-dimensional scanning and tomographic (micro) X-ray powder diffraction. J. Appl. Crystallogr. 2014, 47, 1107-1117. [CrossRef]

18. Sassoni, E.; Graziani, G.; Franzoni, E.; Scherer, G.W. New insights on protective treatments for marble by FIB-SEM. IOP Conf. Ser. Mater. Sci. Eng. 2018, 364, 012092. [CrossRef] 